\title{
Prevalence of long face pattern in Brazilian individuals of different ethnic backgrounds
}

\author{
Mauricio de Almeida CARDOSO', Renata Cristina Faria Ribeiro de CASTRO', Tien LI AN², David NORMANDO³, \\ Daniela Gamba GARIB ${ }^{4}$, Leopoldino CAPELOZZA FILHO \\ 1- DDS, PhD, Professor of Orthodontics, University of Sagrado Coração - USC, Bauru, SP, Brazil. \\ 2- DDS, PhD, Professor in Orthodontics, Department of Dentistry, School of Health Sciences, University of Brasilia, Brasilia, DF, Brazil. \\ 3- DDS, PhD, Assistant Professor, Department of Orthodontics, Brazil Federal University, Belém, PA, Brazil. \\ 4- DDS, PhD, Associate Professor, Department of Pediatric Dentistry, Orthodontics and Community Health, Bauru School of Dentistry, University of São \\ Paulo, Bauru, SP, Brazil.
}

Corresponding address: Dr. Mauricio de Almeida Cardoso, - Universidade do Sagrado Coração - Rua Irmã Arminda, 10-50 - Jardim Brasil - Bauru - SP 17011-160 - Brazil - e-mail: maucardoso@uol.com.br

Received: March 30, 2012 - Modification: January 3, 2013 - Accepted: January 30, 2013

\section{ABSTRACT}

\begin{abstract}
bjective: The long face pattern is a facial deformity with increased anterior total facial height due to vertical excess of the lower facial third. Individuals with long face may present different degrees of severity in vertical excess, as well as malocclusions that are difficult to manage. The categorization of vertical excess is useful to determine the treatment prognosis. This survey assessed the distribution of ethnically different individuals with vertical excess according to three levels of severity and determined the prevalence of long face pattern. Material and Methods: The survey was comprised of 5,020 individuals of Brazilian ethnicity (2,480 females and 2,540 males) enrolled in middle schools in Bauru-SP, Brazil. The criterion for inclusion of individuals with vertically impaired facial relationships was based on lip incompetence, evaluated under natural light, in standing natural head position with the lips at rest. Once identified, the individuals were classified into three subtypes according to the severity: mild, moderate, and severe. Then the pooled sample was distributed according to ethnical background as White (Caucasoid), Black (African descent), Brown (mixed descent), Yellow (Asian descent) and Brazilian Indian (Brazilian native descent). The Chi-square $\left(\chi^{2}\right)$ test was used $(p<0.05)$ to compare the frequency ratios of individuals with vertically impaired facial relationships in the total sample and among different ethnicities, according to the three levels of severity. Results: The severe subtype was rare, except in Black individuals $(7.32 \%)$, who also presented the highest relative frequency $(45.53 \%)$ of moderate subtype, followed by Brown individuals $(43.40 \%)$. In the mild subtype, Yellow $(68.08 \%)$ and White individuals $(62.21 \%)$ showed similar and higher relative frequency values. Conclusions: Black individuals had greater prevalence of long face pattern, followed by Brown, White and Yellow individuals. The prevalence of long face pattern was $14.06 \%$ in which $13.39 \%$ and $0.68 \%$ belonged to moderate and severe subtypes, respectively.
\end{abstract}

Key words: Epidemiology. Long face pattern.

\section{INTRODUCTION}

Long face pattern consists of facial deformities with increased anterior total facial height ${ }^{1,17}$ as a consequence of vertical excess of the lower facial third ${ }^{1,4,11,25}$, which results in an oval ${ }^{10}$ or taper ${ }^{1}$ facial appearance. In this pattern, lip incompetence is mandatory ${ }^{1,4,25}$ and when the lips seal, contraction of the perioral musculature can be evidenced, which accentuates the deficiency of the chin contour ${ }^{1,4,10,23}$ and the appearance of a more retrognathic mandible ${ }^{11,25}$. Gingiva and incisor overexposure occur during smiling ${ }^{4,10,23}$ as a result of anterior and posterior maxillary dentoalveolar growth excess ${ }^{1}$, which constitutes the chief complaint of patients ${ }^{1,10,11,25}$.

Also, a deficiency may be observed in the zygomatic prominence ${ }^{1,25}$ and chin $^{8}$, besides the 
marked nasolabial depression ${ }^{23}$. The length of the upper lip is usually normal ${ }^{10,11,23}$, but it may be short and aggravate the deformity ${ }^{11}$. The lower lip posture is often impaired with excessive lip vermilion display at rest ${ }^{10,11}$. The nose is long ${ }^{1,4,10,11}$, and the nostrils are narrow ${ }^{1,8,11,25}$ with prominent nasal dorsum in lateral view ${ }^{4,10,11,23}$. In this context, the orthodontic treatment alone is very limited, and an orthodontic-surgical approach would be more appropriate ${ }^{9,24}$.

Despite the detailed description of long face pattern in the literature, few studies have investigated the epidemiology of this deformity? A survey performed by the National Center for Health Statistics ${ }^{15}$ showed a prevalence of $1.5 \%$ among North Americans, where $0.75 \%$ of these individuals presented unattractive facial esthetics severe enough for indication of orthodonticsurgical treatment. Similar prevalence was found by another study $(0.6 \%)$ with regard to individuals with a severe long face pattern ${ }^{20}$.

In addition, it is important to consider the prevalence of different degrees of severity in vertical excess that may affect the face considering the great variation of long face problems, ranging from individuals without temporary passive lip sealing due to functional deviations up to individuals who are identified with facial unattractiveness due to long face pattern. The categorization of vertical excess is useful to determine the treatment prognosis.

The differentiation among ethnic groups in an epidemiological survey is of fundamental importance, as many studies reported racial differences in facial features. The Brazilian population presents a variety of ethnic miscegenation, which has been classified as the most heterogeneous population in the world ${ }^{18}$. The State of São Paulo belongs to the Southeast region, which may represent Brazil in terms of its ethnicity distribution ${ }^{19}$. Thus, this survey assessed the distribution of ethnically different individuals with vertically excess according to three levels of severity, and determined the prevalence of long face pattern.

\section{MATERIAL AND METHODS}

In accordance with Resolution 196/96 of the National Health Council, the Declaration of Helsinki and the Nuremberg Code for human experimentation and after approval by the Institutional Review Board of Univ. Estadual Paulista - UNESP at Araçatuba (FOA 2005-01085), the present sample size was calculated considering a $95 \%$ confidence interval and $1.5 \%$ of the estimated prevalence for long face pattern ${ }^{15}$. By assuming that $0.35 \%$ of margin error could exist in the population estimate, a sample size of 4,643 individuals was needed, according to the formula ${ }^{27}$ $n=\underline{z^{2} p q}$. Added to an estimated $10 \%$ of potential

$d^{2}$ loss, a final sample size of approximately 5000 individuals was established to achieve the desired accuracy. The sample size was estimated on the Epiinfo 6.04 software.

The present study was conducted on 5,020 individuals of Brazilian ethnicity enrolled in public and private middle schools ( $5^{\text {th }}$ to $8^{\text {th }}$ grades) in the city of Bauru: 2,480 females (49.40\%) and 2,540 males $(50.60 \%)$ (Table 1$)$. The individuals were aged 10 years to 16 years and 11 months, with a mean age of 13 years ( $S D=1$-year-3-months) for the total sample, 12 years and 11 months $(S D=1$ year and 3 months) for females and 13 years ( $S D=1$ year and 3 months) for males.

Only morphological facial analysis was considered as the basis for the present study. With regard to ethnic classification, the ethnical background may be classified as White, Black, Brown, Yellow and Brazilian Indian, according to the criteria established by the Brazilian Institute of Geography and Statistics (IBGE - Instituto Brasileiro de Geografia e Estatística) ${ }^{5}$. The ethnic distribution among residents in the city of BauruSP and among the evaluated sample is presented in Table 2. Besides the skin color (evaluated in the ventral part of the forearm), the color and texture of the hair, the color of the eyes, and the forms of the lips and mouth were also considered in the classification according to Parra, et al. ${ }^{18}$ (2003).

According to the inclusion criteria, the individual should not present clinically observed syndromes and/or history of surgery, or fractures in the facial or skull region. The history of previous or ongoing orthopedic and/or orthodontic treatment was not an exclusion criterion, because both treatments are unable to significantly change the facial proportions and relationships ${ }^{19,24,26}$. All individuals were evaluated under natural light, in standing natural head position with the lips at rest without the aid of any special equipment, by a single examiner (MAC) experienced in orthodontics and properly calibrated for facial morphology

Table 1- Frequencies of total and evaluated students applied in middle schools in the city of Bauru-SP (Source: Municipal and State Secretary of Education in Bauru, 2005)

\begin{tabular}{ccccc}
\hline Schools & \multicolumn{2}{c}{ Total students } & \multicolumn{2}{c}{ Evaluated students } \\
& $\mathbf{n}$ & $\mathbf{( \% )}$ & $\mathbf{N}$ & $\mathbf{( \% )}$ \\
\hline Municipal & 1,443 & 7.24 & 104 & 2.07 \\
Private & 4,347 & 21.83 & 1,157 & 23.05 \\
State & 14,127 & 70.93 & 3,759 & 74.88 \\
Total & 19,917 & 100 & 5,02 & 100 \\
\hline
\end{tabular}


evaluation ${ }^{11}$

The criterion for identification of patients with vertically impaired facial relationships with excess is morphological, based on lip incompetence, that is, absence of lip sealing at rest ${ }^{1,4,25}$. Once identified, individuals with vertically impaired facial relationships were classified into three subtypes according to the severity as mild, moderate, and severe. The method for this classification has been thoroughly described and has proven to be reliable in a previous study ${ }^{6}$ that demonstrated intra- and inter-examiner agreement.

Classification criteria for the mild subtype included lip incompetence, excessive exposure of maxillary incisors at rest and/or gingiva when smiling, and presence of mild disproportion between the middle and lower facial thirds, even posturally. In summary, these individuals could be considered as transitory long face, postural or even borderline to long face ${ }^{21}$. In this manner, they would present a good prognosis for conservative treatment (orthodontic and/or orthopedic) ${ }^{6}$ (Figure 1).
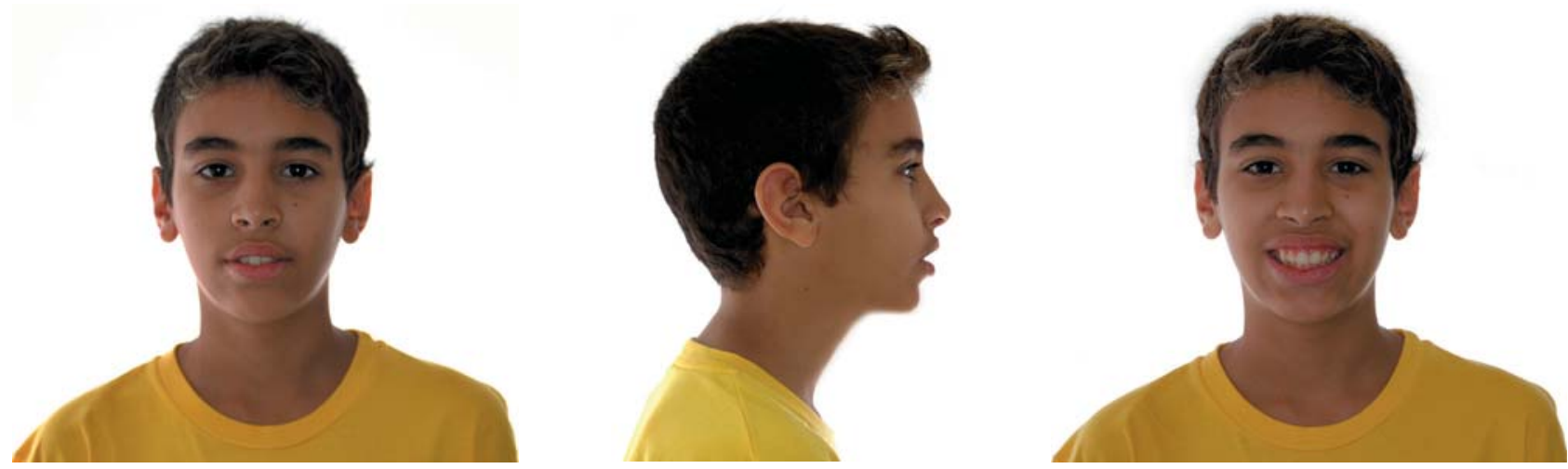

Figure 1- Facial photographs showing the mild subtype individual. Note that vertical facial proportions are balanced even though lip incompetence is observed. Parents signed informed consent for the publication of these pictures
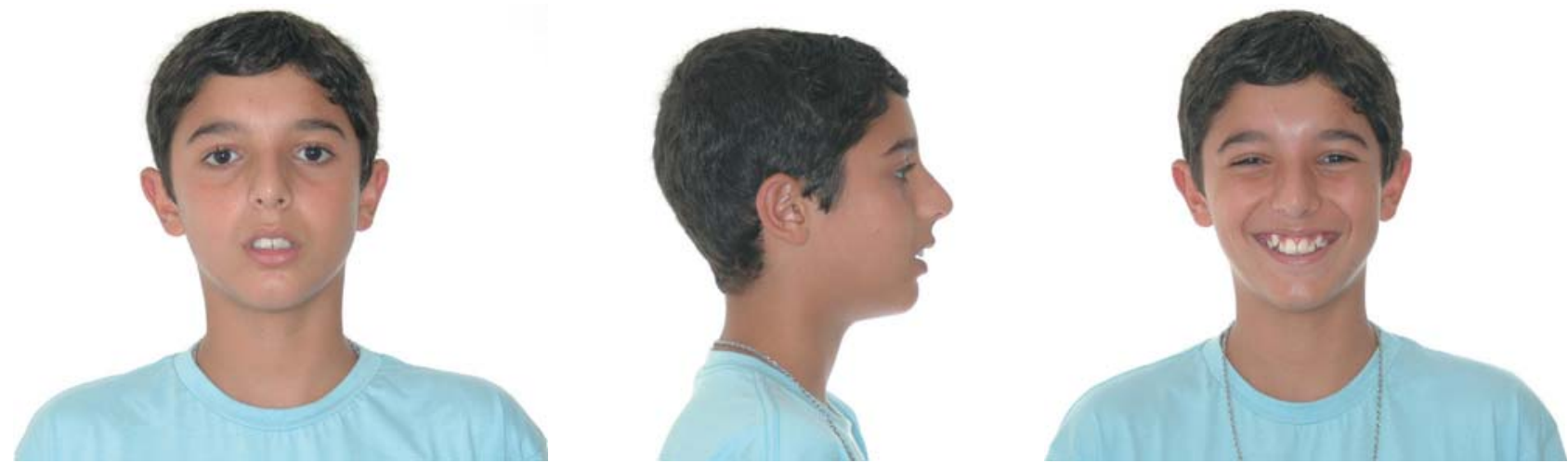

Figure 2- Facial photographs showing the moderate subtype individual. Note that vertical facial proportions are unbalanced. The lower facial height is increased in relation to the middle facial height. Parents signed informed consent for the publication of these pictures
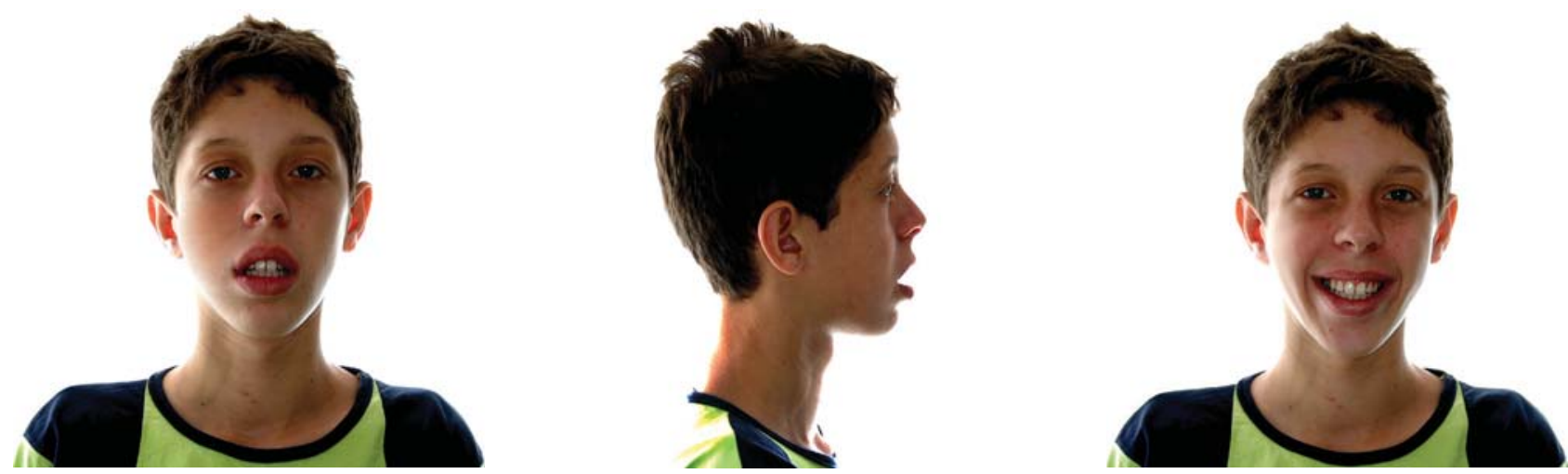

Figure 3- Facial photographs showing the severe subtype individual. Note that vertical facial proportions are unbalanced and all facial esthetic parameters are worse. Parents signed informed consent for the publication of these pictures 
With regard to moderate subtype, the classification criteria were the presence of an actual discrepancy between the middle and lower facial thirds, besides the features already described in the previous subtype, thus certainly characterizing a long face pattern individual. In these individuals, the prognosis is regular for conservative treatment (orthodontic and/or orthopedic) ${ }^{6}$ (Figure 2).

Individuals in the severe subtype should present a severe disproportion between the middle and lower facial thirds, associated with features described in the previous subtype combined to more typical signs of long face, severe enough to cause unattractiveness. In these individuals, the

Table 2- Ethnic distribution of residents and evaluated sample in the city of Bauru-SP (Source: Ministry of Planning, Budget and Management. Brazilian Institute of Geography and Statistics)

\begin{tabular}{ccccc}
\hline Race & $\mathbf{n}$ total & $\%$ & $\begin{array}{c}\mathbf{n} \\
\text { evaluated }\end{array}$ & $\%$ \\
\hline White & 237,925 & 75.67 & 3,559 & 70.90 \\
Brown & 55,504 & 17.65 & 1,041 & 20.73 \\
\hline Black & 15,281 & 4.86 & 279 & 5.56 \\
Yellow & 5,096 & 1.62 & 141 & 2.81 \\
\hline $\begin{array}{c}\text { Brazilian } \\
\text { Indian }\end{array}$ & 625 & 0.20 & 0 & 0 \\
\hline Total & 314,431 & $100 \%$ & 5,020 & $100 \%$ \\
\hline
\end{tabular}

prognosis is poor for conservative treatment, and orthognathic surgery is indicated for normalization of facial relationships ${ }^{6}$ (Figure 3 ).

For statistical processing, all results were analyzed on the Statistica 5.1 software (Stat Soft Inc., Tulsa, USA). The Chi-square $\left(\chi^{2}\right)$ test was used at a significance level of $5 \%(p<0.05)$ to compare the frequency ratios of individuals with vertically impaired facial relationships in the total sample and among different ethnicities, according to the three levels of severity.

\section{RESULTS}

An evaluation of the intra- and inter-examiner error in a previous study ${ }^{6}$ revealed a moderate agreement, evidencing the accuracy of the present methodology. In general, $34.94 \%$ of the pooled sample presents vertical excess and $65.06 \%$ belong to other patterns, either pattern I, II, III or short face. Considering that long face pattern consists of moderate and severe subtypes, $14.06 \%$ of individuals showed long face pattern, in which $0.68 \%$ belonged to the severe subtype (Table 3 ).

When the relative frequencies were analyzed (Table 4), the severe subtype was rare for all ethnicities, except for Black individuals (7.32\%), whose value was three times higher compared to other ethnicities. With regard to the moderate subtype, Black individuals presented the highest relative frequency $(45.53 \%)$, followed by Brown

Table 3- Comparison of the prevalence of individuals with vertical excess and other patterns, according to severity, for each ethnic group

\begin{tabular}{ccccccccccc}
\hline $\begin{array}{c}\text { Pattern } \\
\text { Race }\end{array}$ & \multicolumn{2}{c}{ Mild } & \multicolumn{2}{c}{ Moderate } & \multicolumn{2}{c}{ Severe } & \multicolumn{2}{c}{ Other patterns } & \multicolumn{2}{c}{ Total } \\
\hline & $\mathbf{N}$ & $\%$ & $\mathbf{n}$ & $\%$ & $\mathbf{n}$ & $\%$ & $\mathbf{n}$ & $\%$ & $\mathbf{N}$ & $\%$ \\
\hline White & 726 & 14.46 & 421 & 8.39 & 20 & 0.40 & 2,392 & 47.65 & 3,559 & 70.90 \\
Brown & 232 & 4.62 & 181 & 3.60 & 4 & 0.08 & 624 & 12.43 & 1,041 & 20.73 \\
Yellow & 32 & 0.64 & 14 & 0.28 & 1 & 0.02 & 94 & 1.87 & 141 & 2.81 \\
Black & 58 & 1.16 & 56 & 1.11 & 9 & 0.18 & 156 & 3.11 & 279 & 5.56 \\
Total & 1,048 & 20.88 & 672 & 13.38 & 34 & 0.68 & 3,266 & 65.06 & 5,020 & 100.00 \\
\hline
\end{tabular}

Table 4- Comparison of relative frequencies among individuals with vertical excess, according to severity, for each ethnic group

\begin{tabular}{ccccccccc}
\hline $\begin{array}{c}\text { Severity } \\
\text { Race }\end{array}$ & \multicolumn{2}{c}{ Mild } & \multicolumn{2}{c}{ Moderate } & \multicolumn{2}{c}{ Severe } & \multicolumn{2}{c}{ Total } \\
\hline White & $\mathbf{N}$ & $\%$ & $\mathbf{n}$ & $\%$ & $\mathbf{n}$ & $\%$ & $\mathbf{N}$ & $\%$ \\
\hline Brown & 726 & 62.21 & 421 & 36.08 & 20 & 1.71 & 1,167 & 100.00 \\
Yellow & 232 & 55.64 & 181 & 43.40 & 4 & 0.96 & 417 & 100.00 \\
Black & 32 & 68.08 & 14 & 29.79 & 1 & 2.13 & 47 & 100.00 \\
Total & 58 & 47.15 & 56 & 45.53 & 9 & 7.32 & 123 & 100.00 \\
\hline & 1,048 & 59.75 & 672 & 38.31 & 34 & 1.94 & 1,754 & 100.00 \\
\hline
\end{tabular}


individuals (43.40\%), who were above the average relative frequency of the pooled sample (38.31\%). An opposite situation was observed in the mild subtype, where Yellow (68.08\%) and White individuals $(62.21 \%)$ showed similar and higher relative frequency values.

\section{DISCUSSION}

Facial patterns are primary etiological factors that determine the traces of malocclusions ${ }^{6}$. The long face pattern similarly respects this rule, and malocclusions in individuals with long face are primarily the result of compensation of teeth aiming to camouflage the vertical facial deformity. However, epidemiological surveys in orthodontics, to date, have been directed to the teeth and little information has been reserved to the facial patterns.

According to Hill ${ }^{13}$ (1992), the more complex the survey method, the more errors could be generated. The subjective facial analysis parameters based on the presence or absence of specific conditions for classification are not less validated or less reproducible. This method can be considered as an easier form for survey registration with good reproducibility once the examiners are calibrated ${ }^{6}$.

With regard to the sample, the ethnic distribution can be considered as representative for the city of Bauru-SP, except for the Brazilian Indian group, who are concentrated in the rural area and were not covered in the present survey (Table 2). The ethnic distribution found in our survey cannot be considered as representative for Brazil. Thus, it may represent the distribution of the long face pattern in different races in Bauru, but not of a racial group in Brazil.

The high prevalence of vertical facial excess found in the present survey $(34.94 \%)$ can be explained by the use of lip incompetency as the criterion in the present survey. The lip incompetency is mandatory in long face individuals; however, this characteristic may be frequent during the facial growth period, when it may be considered as normal ${ }^{2}$. For those individuals with temporary lip incompetency, malocclusion may not be present and orthodontic or orthopedic treatment may be unnecessary. To discriminate temporary from permanent lip incompetency, other facial features should be associated for the correct diagnosis ${ }^{6}$. From the three subtypes of vertical facial excess, only moderate and severe subtypes were considered as long face patterns.

According to the prevalence of different severities of vertical facial excess, individuals with mild subtype (20.88\%) were predominant (Table 3 ). Mild subtype individuals (Figure 1) may be different from each other, for who it may be speculated that the primary etiologic factors are not genetic, but local or general.
The mild long face identified at an early age, could be only postural, which morphologically represents a mandatory yet temporary inadequacy between the internal and external functional components.

Individuals with vertical facial excess at moderate and severe levels were classified as long face pattern individuals. A prevalence of $14.06 \%$ of individuals with long face pattern was found in this survey, resulting from the combined prevalence of moderate $(13.38 \%)$ and severe subtypes $(0.68 \%)$ (Table 3 ). Individuals with mild vertical facial excess were not included in the composition of the group of patients with long face pattern because they were classified as having transitory, postural or even borderline long face.

A slightly higher prevalence (4.1\%) was reported in a retrospective study of 1,460 consecutive patients who sought treatment in the orthognathic surgery service in North Carolina (USA) ${ }^{21}$. Since the sample consisted of individuals seeking surgical treatment and the focus of the investigation was facial asymmetry instead of the long face pattern itself, these results may hardly be compared with those found in the present study.

With regard to frequency distribution, White individuals prevailed in all three levels of severity of vertical facial excess. However, this should not be considered as the true prevalence, but a tendency of sampling due to the significant participation of White individuals in the pooled sample. When the relative frequency was analyzed, statistically significant differences were found among ethnicities. Yellow (68.08\%) and White individuals (62.21\%) showed higher frequencies of individuals with mild subtype, followed by the Brown (55.64\%). Black individuals showed the lowest frequency of mild subtype (47.15\%) (Table 4). Among individuals with long face pattern, constituted by moderate and severe subtypes, Black individuals showed the highest prevalence $(7.32 \%)$, followed by Yellow $(2.13 \%)$, White $(1.71 \%)$ and Brown individuals $(0.96 \%)$ (Table 4$)$.

Although the Black ethnic group represented $5.56 \%$ of the total sample, this ethnic group showed the highest frequency of long face pattern. The tendency of increased facial height in Black individuals, of different magnitudes, has already been suggested in some cephalometric studies $^{3,12,16,22}$. Barter ${ }^{3}$ (1995) hypothetically suggested that this increase in facial height was the compensatory mechanism of the mandible that rotates in a clockwise direction to compensate for the growth of the mandibular body. In other words, this morphological characteristic found in the Black ethnicity would predispose to an increase in vertical dimension.

Another survey conducted by the National Center for Health Statistics ${ }^{14}$ on 7,400 American youths 
aged 12 to 17 years found a higher prevalence and severity of anterior open bite in Afro-Americans $(16.3 \%)$ in comparison to White individuals (3.9\%). Despite the limitations inherent to the survey, a great difference has been evidenced in the occlusal characteristics between different ethnic groups. This ethnic dimorphism in the characteristics of occlusion could certainly be extrapolated to facial relationships in such magnitude that still needs to be investigated and understood.

The results obtained from this survey suggest some characteristics with ethnic traits. As Yellow, White and Black ethnic groups are totally distinct from each other and Black individuals also participate in the genealogical line to constitute the Brown individuals ${ }^{18}$, their prevalence of vertical facial excess as well as the severity of the deformity were also peculiar to each ethnic group. In this context, the Brown ethnic group, which usually resulted from the miscegenation of White and Black, may still present remnants of genetic traits of the Black ethnic group. This fact probably explains a greater proportion of individuals with vertical facial excess and long face pattern observed in both ethnicities.

According to a recent demographic census performed in Brazil, there is an evident increase of Brown ethnic individuals, resulting from miscegenation between White ethnic and Brown ethnic individuals as well as the miscegenation between White ethnic and Brazilian Indians ${ }^{5}$. Probably, the genetic traits of the Black ethnicity influenced the Brown ethnicity and also a major portion of Brazilian White individuals that also showed genetic traces of the Black ethnicity ${ }^{18}$. The miscegenation could be credited as one of the reasons explaining why vertical facial excess is highly prevalent among Brazilians compared to other populations in the world. Also, different sampling criteria may result in different prevalence values between the present study and the literature.

In summary, in the prevalence of individuals with long face pattern - moderate and severe subtypes - the Black ethnicity was higher than expected compared to other ethnic groups. This finding demands a critical review of the criteria adopted in the study for morphologic diagnosis in Black individuals. Probably, the morphological criteria used for diagnosis of patients with vertical facial excess in the present survey was magnified for Black individuals. In other words, the determinants of vertical facial excess for other ethnic groups could be considered as normal for Black individuals based on the proposed criteria for facial morphological analysis. This premise has been confirmed by Barter, et al. ${ }^{3}$ (1995). Other studies with only Black ethnicities should be carried out to elucidate this hypothesis.

\section{CONCLUSIONS}

In descending order of relative frequencies, Black individuals had greater prevalence of long face pattern, followed by Brown, White and Yellow individuals. Only a small percentage of individuals $(<1 \%)$ presented severe subtypes in all the ethnic groups. The prevalence of long face pattern was $14.06 \%$ in the population, in which $13.39 \%$ and $0.68 \%$ belonged to moderate and severe subtypes, respectively.

\section{REFERENCES}

1- Angelillo JC, Dolan EA. The surgical correction of vertical maxillary excess (long face syndrome). Ann Plast Surg. 1982;8:6470

2- ASHA. American Speech Language Hearing Association. The role of the speech language pathologist in assessment and management of oral myofunctional disorders. Asha. 1991;33(suppl. 5):7.

3- Barter MA, Evans WG, Smit GL, Becker PJ. Cephalometric analysis of a Sotho-Tswana group. J Dent Assoc. 1995;50:539-44. 4- Bell WH, Creekmore TD, Alexander RG. Surgical correction of the long face syndrome. Am J Orthod. 1977;71:40-67.

5- Brasil. Ministério do Planejamento, Orçamento e Gestão. Instituto Brasileiro de Geografia e Estatística. Tabulação avançada do censo demográfico 2000: resultados preliminares da amostra/ IBGE. Rio de Janeiro: IBGE; 2002. 174 p.

6- Capelozza L Filho, Cardoso MA, An TL, Lauris JRP. Proposal for classification of individuals with long face pattern malocclusions according to severity. Rev Dental Press Ortod Ortop Facial. 2007; 12(4):124-58.

7- Cardoso MA, Capelozza L Filho, An TL, Lauris JRP. Epidemiology of long face pattern in school children attending middle schools in the city of Bauru-SP. Dental Press J Orthod. 2011;16:108-19. 8- Epker BN, Fish LC. Surgical-orthodontic correction of open-bite deformity. Am J Orthod. 1977;71:278-99.

9- Fields HW, Proffit WR, Nixon WL, Phillips C, Stanek E. Facial pattern differences in long-faced children and adults. 1984;85:217-23.

10- Fish LC, Wolford LM, Epker BN. Surgical-orthodontic correction of vertical maxillary excess. Am J Orthod. 1978;73:241-57.

11- Fitzpatrick BN. The long face and V. M. E. Aust Orthod J. 1984;8:82-9.

12- Freitas LM, Pinzan A, Janson G, Freitas KM, Freitas MR, Henriques JFC. Facial height comparison in young white and black Brazilian subjects with normal occlusion. Am J Orthod Dentofacial Orthop. 2007;131:706.e1-e6.

13- Hill PA. The prevalence and severity of malocclusion and the need for orthodontic treatment in 9-, 12-, and 15-year-old Glasgow schoolchildren. Br J Orthod. 1992;19:87-96.

14- Kelly JE, Harvey C. An assessment of the teeth of youth 1217 years. Washington, DC: National Center for Health Statistics; 1977. p.1-18.

15- Kelly JE, Sanchez M, Van Kirk LE. An assessment of the occlusion of teeth of children 6-11 years: United States. National Center for Health Statistics. Vital Health Stat. 1973:130:2-7.

16- Naidoo LCD, Miles LP. An evaluation of the mean cephalometric values for orthognathic surgery for Black South Africa adults. Part I: Hard tissue. ] Dent Assoc. 1997;52:495-502.

17- Nielsen IL. Vertical malocclusions: etiology, development, diagnosis and some aspects of treatment. Angle Orthod. 1991;61:82-9.

18- Parra FC, Amado RC, Lambertucci JR, Rocha J, Antunes CM, Pena SDJ. Color and genomic ancestry in Brazilians. Proc Natl Acad Sci. 2003;100:177-82. 
19- Pena SDJ, Silva DRC, Silva JA, Prado VF. Retrato molecular do Brasil. Cienc Hoje. 2000;27:16-25.

20- Proffit WR, Fields HW, Moray LJ. Prevalence of malocclusion and orthodontic treatment need in the United States: estimates from the N-HANES III survey. Int J Adult Orthod Orthogn Surg. 1998; 13:97-106.

21- Proffit WR, Mason RM. Myofunctional therapy for tonguethrusting: background and recommendations. J Am Dent Assoc. 1975;90:403-11.

22- Rosa RA, Arvystas MG. An epidemiologic survey of malocclusions among American Negroes and American Hispanics. Am J Orthod. 1978;73:258-73.
23- Schendel SA, Eisenfeld J, Bell WH, Epker BN, Mishelevich DJ. The long face syndrome: vertical maxillary excess. Am J Orthod. 1976; 70:398-408.

24- Van Der Linden PGM. O desenvolvimento das faces longas e curtas e as limitações do tratamento. Rev Dental Press Ortod Ortop Facial. 1999;4:6-11.

25- Wolford LM, Hilliard FW. The surgical-orthodontic correction of vertical dentofacial deformities. J Oral Surg. 1981;39:883-97. 26- Woodside DG, Linder-Aronson S. The chanelization of upper and lower anterior face heights compared to population standard in males between ages 6 to 20 years. Eur J Orthod. 1979;1:25-40. 27- Zar JH. Biostatistical analysis. $3^{\text {rd }}$. ed. Upper Saddle River: Prentice-Hall; 1996. 662 p. 